\title{
Dyeing and Color Fastness Properties of Natural Dyed Actual Size Hanji
}

\author{
JeongKwan $\mathrm{ROH}^{1, \uparrow} \cdot$ Hyun-Jin $\mathrm{JO}^{2}$
}

\begin{abstract}
After manufacturing the natural dyed actual size Hanji using 11 kinds of plant natural dyeing materials and 2 kinds of animal natural dyeing materials, the color characteristics and color change and color fastness after post-mordanting were compared and discussed. The hues of 13 types of natural dyed Hanji were black, PB, and RP, each with 1 type, YP with 3 types, and Y with 7 types. Among the natural dyeing materials, Chinese ink, indigo and Lac showed high color yield and color difference, and violet-root cromwell and gardenia seeds showed low color yield. The color fastness of Hanji dyed with turpentine diluted Ottchil, Pagoda tree seeds, Chinese ink and indigo was excellent, while that of gardenia seeds and violet-root cromwell were very poor. After post-mordanting of natural dyed Hanji with $\mathrm{Al}, \mathrm{Cu}$, and Fe mordants, the hue changes were show up the Alnus firma, clove, lac and cochineal. In addition, the color difference was very diverse and was overall the most biggest due to Fe mordant. After $72 \mathrm{hr}$. of UV irradiation on post-mordanting natural dyed Hanji, hue change was observed in 3 types and color fastness was improved in 8 types by post-mordanting. The Hue and color fastness are significantly different depending on the type of natural dying materials and post-mordants. Therefore, when dyeing Hanji with natural dyes, it is necessary to dye with sufficient knowledges and informations about the desired color and fastness.
\end{abstract}

Keywords: Hanji, natural dyeing materials, post-mordanting, color difference, color yield, color fastness

\section{INTRODUCTION}

Paper was reportedly introduced to Korea between the 2 nd and 7 th centuries, since paper was manufactured systematically using fibers from the tree bark and hemp by Chaeryun around $105 \mathrm{AD}$. The culture and manufacturing technology of Korean ancestors for using paper and wood products were quite excellent (Han and Lee, 2021a, 2021b; Han et al., 2021; Yoon et al., 1996).
Hanji (Korean traditional paper) from the Goryeo Dynasty is considered to be of a superior quality because the raw material of the paper is the fiber from tree mulberry and the mucilage from sunset hibiscus is used as a fiber dispersant. Other possible reasons include the bleaching method minimizing damage to the fibers, the water used during the Hanji making and washing processes, and a unique Hanji making method (Heullim tteugi), which leads the fibers' orientation in perpendicular to

Date Received December 20, 2021, Date Revised December 30, 2021, Date Accepted December 30, 2021

${ }^{1}$ Department of Interior Materials Engineering, Gyeongsang National University, Jinju 52725, Korea

2 Jo Hyun-Jin Hanji Research Center, Jinju 52828, Korea

† Corresponding author: JeongKwan ROH (e-mail: arjk@gnu.ac.kr, https://orcid.org/0000-0002-3146-951X)

(C) Copyright 2022 The Korean Society of Wood Science \& Technology. This is an Open-Access article distributed under the terms of the Creative Commons Attribution Non-Commercial License (http://creativecommons.org/licenses/by-nc/4.0/) which permits unrestricted non-commercial use, distribution, and reproduction in any medium, provided the original work is properly cited. The Korean translation of this article can be found at the following address. https://doi.org/10.5658/wood.korean 
each other. Hanji quality has also significantly changed according to the times, functions, and purposes, and while records of hundreds of different types of papers have appeared in ancient documents, however, little data is available regarding their manufacturing methods.

In literature records and relics, different types of Hanji are called by different names depending on the material, use, color, manufacturing region, and processing method. In particular, a lot of Hanjis are dyed as a method to impart diversity, aesthetics, and functionality.

Among the colored papers that appear in the ancient documents, red-colored papers include Do-Wha-Ji (桃花 紙), Dan-Mok-Ji (丹木紙), Hong-Jeo-Ju-Ji (紅楮注紙), Hong-Dang-Ji (紅唐紙), Hong-Pae-Ji (紅牌紙), and MaeHong-Ji (梅紅紙)， blue-to-green-colored papers include Cheong-Jeo-Ju-Ji (靑楮注紙), Ah-Cheong-Cho-Ju-Ji (鴉 靑草注紙)，Cheong-Saek-Ji (靑色紙)，Cheong-Dang-Ji (靑唐紙)，Cheong-Bak-Ji (靑筞紙)，Cheong-Seon-Ja-Ji (靑扇子紙), Ah-Cheong-Ji (鴉青紙), Chi-Ji (翠紙), ChoRok-Ji (草綠紙), and Cho-Rok-Jeo-Ju-Ji (草綠楮注紙);， yellow-colored papers include Whang-Guk-Ji (黃菊紙), Whang-Jeo-Ju-Ji (黃楮注紙)，Whang-Yeom-Cho-Ju-Ji (黃染草注紙), and Sang-Ji (橡紙), black-colored Hanji is Mook-Ji, gold-colored Hanji is Hanji coated with gold powder (冷金箋紙), and silver Hanji is coated with silver foil (銀箋紙). Unfortunately, although a large variety of colored Hanji used to exist, there are hardly any records of the natural dyes and methods that were used to manufacture them. As natural dyes for manufacturing colored Hanji, for red color, Safflower, Madder, dried Violet-root cromwell, and Sappan wood were used; for blue, Indigo and Ninam were used; for yellow, Pagoda tree, Amur cork-tree, Barberry root, Gardenia, and smoke tree were used. The dyes primarily used for black include gallnut, Amur maple, and Chinese ink (Meok).

Natural dyes used in the study for manufacturing natural dyed Hanji include Amur cork-tree (Choi, 2006), Clove tree (Jeon et al., 2006), Alder fruit (Choi et al., 2009), Gardenia (Yoo et al., 2011), Sappan wood,
Gallnut (Park and Yoon, 2009, 2010, 2011), Pagoda tree (Yoo et al., 2009), Onion peel (Jeon, 2003), Mugwort (Jeon et al., 2006), Neolitsea sericea (Jo et al., 2007), Smoke tree (Lee et al., 2009), Persimmon juice (Yoo et al., 2010), Chestnut husk, Gallnut (Lee et al., 2009), etc. In addition, Gardenia and Sappan wood (Ju and Roh, 2020) have been used for regenerated wood fibers.

In general, the strength of Hanji depends on the fiber direction, the degree of lamination, and the coating, but the wet strength is weaker than that of the fabrics (Jeon, 1999, 2002). Therefore, most studies on natural dyeing have been mainly conducted on small-sized Hanji or fabric because Hanji, which has very weak wet strength compared to fabrics, is easily torn when immersed in a dye solution and dyed, and is rarely dyed once, and there are many cases of damage in the process of repeating several times. In addition, Hanji is more prone to damage when dyeing with a large one without cutting.

In this study, 13 types of natural dyed Hanji were manufactured using 11 types of natural plant ingredients and 2 types of natural animal materials that have previously not been applied to Hanji, and their color characteristics were compared and analyzed. Thereafter, color change due to post-mordanting, and color and fastness due to the type of natural dye used were reviewed.

\section{MATERIALS and METHODS}

\subsection{Hanji}

Hanji dyeing with natural dyes, has weak wet strength, must be conducted very carefully and is easy to fail unless Hanji prepared in the traditional way is used. It is more difficult to dye the big Hanji $(66 \mathrm{~cm} \times 94 \mathrm{~cm})$ as it is manufactured. In this study, Hanji manufactured by a Hanji artisan with Heullim tteugi was purchased for natural dyeing, which was $66 \mathrm{~cm} \times 94 \mathrm{~cm}$ in the size with the weight of $28-30 \mathrm{~g} / \mathrm{m}^{2}$. 


\subsection{Natural dyeing materials}

As a natural dye for Hanji, plant materials such as Gardenia seeds, Amur cork-tree bark, Alnus firma fruit, Pagoda tree seed, Sappan wood, Violet-root cromwell, Indigo, Meok, Clove tree, and Ottchil (Oriental lacquer diluted with ethanol or turpentine) and animal materials such as Cochineal and Lac were used. Dyeing is a post-dyeing method in which a dye solution is extracted in consideration of the characteristics of the natural dye material, then immersed in the dye solution for a certain period, and repeated as needed. The type number, scientific or English name, and density of each dyed Hanjis are shown in Table 1. The density of Hanji was 0.35 $\mathrm{g} / \mathrm{cm}^{3}$, and after dyeing, only the density of Indigo-dyed Hanji slightly increased while the rest decreased.

\subsection{Dyeing with natural ingredients}

\subsubsection{Ottchil (No. 2, 3)}

Raw oriental lacquer was purchased and stored at $5{ }^{\circ} \mathrm{C}$ or lower before use. Ottchil solution (Park et al., 2020), typically used for coating wood products, was prepared by diluting 1,000 $\mathrm{g}$ of Ottchil in $10 \mathrm{~L}$ of turpentine (TP) and ethanol (ET). Each solution was placed in a separated stainless-steel container and Hanji was immersed in the solutions for $10 \mathrm{~min}$., to prepare two types of Ottchil-dyed Hanji (TP, ET).

\subsubsection{Alnus firma fruit (No. 4)}

The seeds of Alnus firma tree, i.e., strobilus, which were hung after the leaves fell in winter were collected from Jinju, Gyeongsangnam-Do, and used further. $10 \mathrm{~L}$ of water was added to $500 \mathrm{~g}$ of strobilus, boiled over high heat, simmered over low heat for another $20 \mathrm{~min}$., and finally the dye-extracted solution was filtered. Again, $10 \mathrm{~L}$ water was added to the strobilus and the extraction process was repeated four times. The final extract was mixed and used as a dyeing solution. For the dyeing process, the extracted dyeing solution was placed in a square stainless-steel container, and Hanji was immersed

Table 1. Type number, Korean name, and scientific or common name of natural dyeing materials used to dye the Hanji

\begin{tabular}{cllc}
\hline $\begin{array}{c}\text { Type } \\
\text { no. }\end{array}$ & Korean name & \multicolumn{1}{c}{ Scientific or common name } & $\begin{array}{c}\text { Density of Hanji, } \\
\text { after } \\
\left(\mathrm{g} / \mathrm{cm}^{3}\right)\end{array}$ \\
\hline \hline 1 & 원지, 한지 & Control, Hanji & 0.35 \\
2 & 옻 TP(테레빈유) & Ottchil (Turpentine) & 0.34 \\
3 & 옻 ET(에탄올) & Ottchil (Ethanol) & 0.32 \\
4 & 사방오리나무 열매 & Alnus firma Sieb. et Zucc., Alnus firma fruit & 0.33 \\
5 & 치자 열매 & Gardenia jasmininoides, Gardenia seeds & 0.32 \\
6 & 괴화나무 열매 & Sophora japonica L., Pagoda tree seeds & 0.32 \\
7 & 정향나무 & Eugenia caryophyllata, Clove tree & 0.32 \\
8 & 황벽나무 수피 & Phellodendron amurense Rupr., Amur cork-tree bark & 0.32 \\
9 & 먹 & Meok, Chinese ink & 0.32 \\
10 & 쪽 & Persicaria tinctoria (Aiton) H. Gross, Indigo & 0.36 \\
11 & 락 & Laccifer lacca, Kerria lacca, Lac & 0.31 \\
12 & 자초 뿌리 & Lithospermum erythrorhizon Sieb. et Zucc., Violet-root cromwell & 0.31 \\
13 & 코치닐 & Coccus cacti L. Cochineal & 0.31 \\
14 & 소목 & Caesalpinia sappan L., Sappan wood & 0.31 \\
15 & 복사 용지 & Copy paper & 0.70 \\
\hline
\end{tabular}


twice at $50^{\circ} \mathrm{C}-60^{\circ} \mathrm{C}$ for $15 \mathrm{~min}$.

\subsubsection{Gardenia seeds (No. 5)}

Gardenia seeds $(500 \mathrm{~g})$ grown and dried in Jinju, Gyeongsangnam-Do were soaked in $10 \mathrm{~L}$ water for one day, boiled over high heat, simmered over low heat for about $20 \mathrm{~min}$., and filtered to obtain an extract. Again, $10 \mathrm{~L}$ of water was added, and the extract obtained by repeating the same process thrice was combined and used as a dyeing solution for Gardenia seeds. Dyeing was performed for $15 \mathrm{~min}$., by immersing Hanji in the dyeing solution at $50^{\circ} \mathrm{C}-60^{\circ} \mathrm{C}$, and repeated twice.

\subsubsection{Pagoda tree seeds (No. 6)}

Pagoda tree (Sophora) seeds of $100 \mathrm{~g}$ that were purchased from oriental medicine store were soaked in $2 \mathrm{~L}$ water for approximately $1 \mathrm{hr}$. Thereafter, another 2 $\mathrm{L}$ of water was added, and the mixture was boiled over high heat, maintained over low heat for $15 \mathrm{~min}$., and filtered to obtain an extract. Water (2 L) was added again, and the extract obtained by repeating the same method thrice was used as a dyeing solution. For the dyeing process, the extracted dyeing solution was placed in a square stainless-steel container, and Hanji was immersed twice at $50^{\circ} \mathrm{C}-60^{\circ} \mathrm{C}$ for $15 \mathrm{~min}$.

\subsubsection{Clove tree (No. 7)}

Clove tree $(200 \mathrm{~g})$ was bought from an oriental medicine store and washed with water. Thereafter, $10 \mathrm{~L}$ of water was added, boiled, simmered over low heat for another 20 min., and filtered down to obtain an extract. Again, $10 \mathrm{~L}$ water was added, and the extract obtained by repeating the same method thrice was used as a dyeing solution. For the dyeing process, the extracted dyeing solution was placed in a square stainless-steel container, and Hanji was immersed thrice at $50^{\circ} \mathrm{C}-60^{\circ} \mathrm{C}$ for $15 \mathrm{~min}$.

\subsubsection{Amur cork-tree bark (No. 8)}

Water (4 L) was added to $100 \mathrm{~g}$ of Amur cork-tree bark purchased at an oriental medicine store, boiled over high heat, and simmered over low heat for an additional $20 \mathrm{~min}$. Thereafter, the extract was separated by filtration, $4 \mathrm{~L}$ of water was added, and the extract obtained by repeating the same process thrice was used as a dyeing solution. For the dyeing process, the extracted dyeing solution was placed in a square stainless-steel container, and Hanji was immersed thrice at $50^{\circ} \mathrm{C}-60^{\circ} \mathrm{C}$ for $15 \mathrm{~min}$.

\subsubsection{Meok (No. 9)}

A dye solution was prepared by mixing the Chinese ink purchased from a stationery store with water in a 1:10 ratio. For the dyeing process, the extracted dyeing solution was placed in a square stainless-steel container, and Hanji was immersed twice at $40^{\circ} \mathrm{C}-50^{\circ} \mathrm{C}$ for $15 \mathrm{~min}$.

\subsubsection{Indigo (No. 10)}

For Indigo, an imported Indigo powder was purchased and used. Indigo dye solution contained $100 \mathrm{~g}$ powdered Indigo dissolved in $300-\mathrm{mL}$ water at $60^{\circ} \mathrm{C}-70^{\circ} \mathrm{C}$ and 200 g potassium carbonate in $300 \mathrm{~mL}$ water at $60^{\circ} \mathrm{C}-70^{\circ} \mathrm{C}$ in a stainless-steel container containing $1,100 \mathrm{~mL}$ water at $50^{\circ} \mathrm{C}-60^{\circ} \mathrm{C}$. The prepared solution and $200 \mathrm{~g}$ hydrosulfite dissolved in $300 \mathrm{~mL}$ water at $60^{\circ} \mathrm{C}-70^{\circ} \mathrm{C}$ were sequentially added, followed by mixing. Further, Hanji was dip dyed in an Indigo dye solution at $50^{\circ} \mathrm{C}-60^{\circ} \mathrm{C}$ for $15 \mathrm{~min}$., followed by oxidative color development in air for $20 \mathrm{~min}$. This process was repeated five times, and finally washed with water thrice.

\subsubsection{Lac (No. 11)}

Lac from a dye material dealer was purchased and used. $50 \mathrm{~g}$ of Lac resin finely ground with a grinder was placed in $10 \mathrm{~L}$ of water with $100 \mathrm{~mL}$ of vinegar, boiled over high heat, simmered over low heat for $15 \mathrm{~min}$., and then filtered to obtain a solution. Thereafter, water was 
added again, and the solution obtained in the same way was combined and used as the Lac dye solution. For the dyeing process, the extracted dyeing solution was placed in a square stainless-steel container, and Hanji was immersed twice at $50^{\circ} \mathrm{C}-60^{\circ} \mathrm{C}$ for $15 \mathrm{~min}$.

\subsubsection{Violet-root cromwell (No. 12)}

Domestic grown Violet-root cromwell was purchased, dried, and used. Dried Violet-root cromwell (200 g) was washed and added to $4 \mathrm{~L}$ of water at $40^{\circ} \mathrm{C}$ with $30 \mathrm{~mL}$ of vinegar, and it was soaked for $20 \mathrm{~min}$. and scooped out. Thereafter, the Violet-root cromwell removed with a wooden bat was beaten, put in a burlap bag, and rubbed in water at $40^{\circ} \mathrm{C}-50^{\circ} \mathrm{C}$ to extract the dye solution. Further, the Violet-root cromwell residue was put back into water, extracted the same way thrice, and the obtained solution was mixed and used as the Violet-root cromwell dyeing solution. For the dyeing process, the extracted dyeing solution was placed in a square stainless-steel container, and Hanji was immersed at $40^{\circ} \mathrm{C}-50^{\circ} \mathrm{C}$ for $15 \mathrm{~min}$., dried, and this process was repeated thrice.

\subsubsection{Cochineal (No. 13)}

Cochineal was purchased from a dye material supplier. Finely grounded with a grinder, $100 \mathrm{~g}$ of cochineal was put into $10 \mathrm{~L}$ of water with $100 \mathrm{~mL}$ vinegar, boiled over high heat, simmered over low heat for 15 min., and filtered to obtain a solution that was used as the dyeing solution. For the dyeing process, the extracted dyeing solution was placed in a square stainless-steel container, and Hanji was immersed at $50^{\circ} \mathrm{C}-60^{\circ} \mathrm{C}$ for $15 \mathrm{~min}$., dried, and this process was repeated twice.

\subsubsection{Sappan wood (No. 14)}

Sappan wood was purchased from an oriental medicine store. For the Sappan wood dye solution, $100 \mathrm{~g}$ of Sappan wood was pre-soaked in about $2 \mathrm{~L}$ of water for $1 \mathrm{hr}$., thereafter, more $2 \mathrm{~L}$ of water was added, boiled over high heat, simmered over low heat for $15 \mathrm{~min}$., and filtered to obtain an extract. Thereafter, $4 \mathrm{~L}$ of water was added, and the extract obtained by repeating extraction thrice in the same way was mixed and used as the Sappan wood dyeing solution. For the dyeing process, the extracted dyeing solution was placed in a square stainless-steel container, and Hanji was immersed at $50^{\circ} \mathrm{C}-60^{\circ} \mathrm{C}$ for $15 \mathrm{~min}$., dried, and this process was repeated thrice.

\subsubsection{Copy paper (No. 15)}

Copy paper used for comparison was white paper with a basis weight of $75 \mathrm{~g} / \mathrm{m}^{2}$.

\subsection{Mordanting of natural dyed Hanji}

For post-mordanting, aluminum ammonium sulfate dodecahydrate, Copper (II) acetate anhydrous, Iron(II) sulfate heptahydrate (Extra pure, Daejung) were added at 5\% (O.W.F) of the Hanji weight and 50:1 liquid ratio as mordants, treated at $40^{\circ} \mathrm{C}$ for $30 \mathrm{~min}$., and washed with distilled water thrice.

\subsection{Measurement of color characteristics}

The surface color of natural dyed Hanji was measured using Minolta CM-3800d (Tyoko, Japan). The color difference of Hanji treated here was calculated based on the color of Hanji before dyeing for the dyed Hanji, dyed Hanji before mordanting for the mordanted dyed Hanji, and dyed and/or mordanted Hanji before UV irradiation for UV irradiated dyed and/or mordanted Hanji, respectively. The K/S value was calculated by the Kubelka-Munk equation after measuring the reflectance coefficient of each dyed sample.

\subsection{Evaluation of color fastness}

The color fastness of the natural dyed Hanji was measured using an accelerated weathering tester (QUV/ SP, USA) before and after UVB-313 lamp, illuminance 
of $0.67 \mathrm{~W} / \mathrm{m}^{2}$, and UV irradiation treatment at $50^{\circ} \mathrm{C}$ for a certain period. The color difference was evaluated in the CIE Lab color space, typically used to indicate the standard color space for wood products (Hadi et al., 2020; Lee and Lee, 2021; Priadi et al., 2020).

\section{RESULTS and DISCUSSION}

\subsection{Color characteristics and fastness of natural dyed Hanji}

\subsubsection{Color characteristics}

The hue $(\mathrm{H})$ of Hanji before dyeing was 4.3Y, and the $\mathrm{L}^{*}$ and $\mathrm{V}$ values were very high, indicating a yellowish color that was close to white. Table 2 and Fig. 1 show the color characteristics of the actual size Hanji, dyed with 13 natural dyes. Among all the natural dyes, Chinese ink, Indigo, and Lac showed high dyeing yield and color difference, and Lac showed significantly high color difference compared to the dyeing yield. Conversely, the dyeing yield was less than 1 for Violet-root cromwell and Gardenia seeds, and the color difference was less than 10.0 for Pagoda tree seeds, Clove tree, and turpentine-diluted Ottchil.

Among the Hanjis dyed with the 13 dyes, Hanji dyed with two types of Ottchil, Alnus firma fruit, Gardenia tree seeds, Pagoda tree seeds, and Clove tree presented a yellow color $(\mathrm{H})$ of $1.2-4.7 \mathrm{Y}$. Amur cork-tree bark expressed a yellow color close to green at 9.8Y. The dyeing yield values of these seven natural yellow dyes was in the range of 1.0 to 4.19 , the highest in Alnus firma fruit and the lowest in Gardenia tree seeds extract. The color difference of post- dyeing Hanji was in between 5.5 and 19.3, which was high in ethanol-diluted Ottchil, Alnus firma fruit, Gardenia tree seeds, and Amur cork-tree bark in the order, and was low in the order of Pagoda tree seeds, Clove tree, and terpentine-diluted Ottchil. Chinese ink-dyed Hanji showed extremely high dyeing yield and color difference and its Munsell's value was V 2.82 and C 0.42 .

Indigo-dyed Hanji (5 times dyed), which was dyed more 2-3 times than the others, showed 6.04 in the dyeing yield and 53.3 in the color difference so that it ranked in the second highest place after Meok. Its hue was a blue type (3.7PB) and $\mathrm{a}^{*}$ and $\mathrm{b}^{*}$ were -2.64 and -14.32 , respectively.

The hue of Hanji dyed with Lac, a natural animal dye, was 7.7RP and $\mathrm{a}^{*}$ was as large as 19.6 and $\mathrm{b}^{*}$ was 1.1, indicating red purple. The hues of Hanji dyed with plant dye Violet-root cromwell and Sappan wood and an animal dye cochineal were 5.8YR, 3.2YR, and 8.2YR, respectively, indicating a yellow red. The dyeing yield

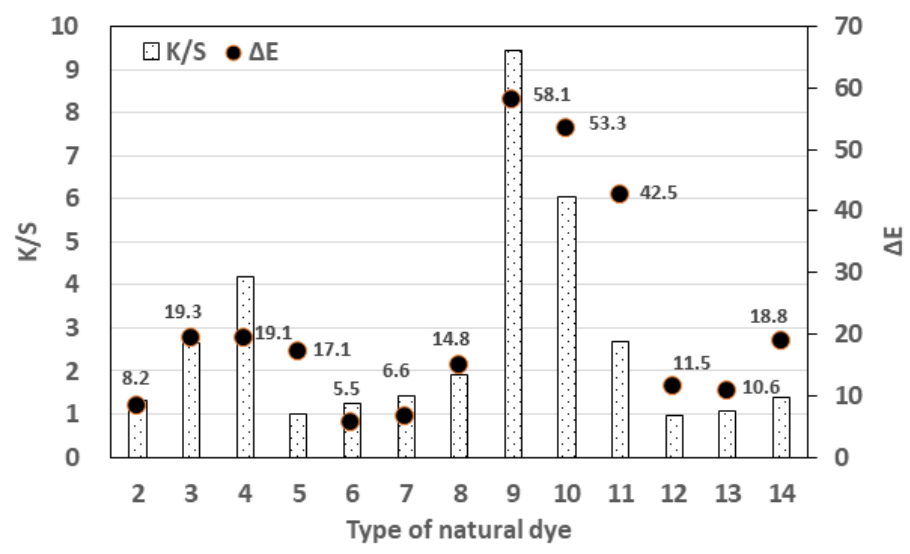

Fig. 1. Dyeing yield $(K / S)$ and color difference $(\Delta E)$ of various natural dyed Hanjis. 
Table 2. Color characteristics of various natural dyed Hanjis

\begin{tabular}{|c|c|c|c|c|c|c|c|c|c|}
\hline \multirow{2}{*}{$\begin{array}{l}\text { Type of } \\
\text { natural dye }\end{array}$} & \multirow{2}{*}{$\begin{array}{c}\lambda \max \\
(\mathrm{nm})\end{array}$} & \multirow{2}{*}{$\mathrm{K} / \mathrm{S}$} & \multicolumn{4}{|c|}{ CIE Lab } & \multicolumn{3}{|c|}{ Munsell's value } \\
\hline & & & $\mathrm{L}^{*}$ & $a^{*}$ & $b^{*}$ & $\Delta \mathrm{E}$ & $\mathrm{H}$ & V & $\mathrm{C}$ \\
\hline 1 & 360 & 0.49 & 86.81 & -0.30 & 7.96 & & $4.3 \mathrm{Y}$ & 8.58 & 0.94 \\
\hline 2 & 360 & 1.32 & 84.56 & -0.09 & 15.86 & 8.21 & $4.0 \mathrm{Y}$ & 8.37 & 2.02 \\
\hline 3 & 360 & 2.66 & 75.33 & 4.27 & 22.78 & 19.25 & $1.2 \mathrm{Y}$ & 7.45 & 3.44 \\
\hline 4 & 360 & 4.19 & 77.11 & 2.83 & 24.20 & 19.14 & $2.3 \mathrm{Y}$ & 7.63 & 3.50 \\
\hline 5 & 360 & 1.00 & 84.33 & 0.52 & 24.82 & 17.06 & $4.7 \mathrm{Y}$ & 8.39 & 3.41 \\
\hline 6 & 360 & 1.23 & 85.40 & -0.33 & 13.29 & 5.50 & $3.9 \mathrm{Y}$ & 8.45 & 1.64 \\
\hline 7 & 360 & 1.40 & 85.45 & -0.28 & 14.44 & 6.61 & $4.2 \mathrm{Y}$ & 8.46 & 1.80 \\
\hline 8 & 360 & 1.91 & 86.38 & -4.31 & 22.18 & 14.79 & $9.8 \mathrm{Y}$ & 8.57 & 2.75 \\
\hline 9 & 370 & 9.44 & 28.92 & 0.68 & 2.57 & 58.05 & & 2.82 & 0.42 \\
\hline 10 & 650 & 6.04 & 38.30 & -2.64 & -14.32 & 53.34 & $3.7 \mathrm{~PB}$ & 3.67 & 3.45 \\
\hline 11 & 530 & 2.69 & 49.74 & 19.58 & 1.10 & 42.54 & 7.7RP & 4.84 & 4.93 \\
\hline 12 & 360 & 0.96 & 76.07 & 4.01 & 7.84 & 11.49 & $5.8 \mathrm{YR}$ & 7.49 & 1.57 \\
\hline 13 & 360 & 1.05 & 78.26 & 5.81 & 8.82 & 10.57 & $3.2 \mathrm{YR}$ & 7.71 & 2.15 \\
\hline 14 & 360 & 1.39 & 76.93 & 8.63 & 21.23 & 18.77 & $8.2 \mathrm{YR}$ & 7.62 & 3.75 \\
\hline 15 & 360 & 0.94 & 91.70 & 2.78 & -12.83 & 21.59 & & 9.02 & 3.94 \\
\hline
\end{tabular}

increased in the order of Sappan wood, cochineal, and Violet-root cromwell.

\subsubsection{Color fastness}

Table 3 shows the color fastness after $72 \mathrm{hr}$. UV irradiation on the undyed Hanji and dyed Hanji with each natural dye. Even with the harsh UV irradiation at $50^{\circ} \mathrm{C}$ for $72 \mathrm{hr}$., the small color difference implied good color fastness. The color difference of undyed Hanji after 72 hr. of UV irradiation was 2.23 , indicating even undyed Hanji also underwent color change by UV rays. Among these 13 natural dyed Hanji, the ones with less color difference than the undyed Hanji were turpentine-diluted Ottchil, Pagoda tree seeds, Meok, and Indigo-dyed Hanji. The color difference of Meok-dyed Hanji was 0.03. It implies the color of Meok-dyed Hanji could be maintained without fading away even after $72 \mathrm{hr}$. of UV irradiation. In addition, the color difference of Pagoda tree seeds and Indigo-dyed Hanji was also less than 1, indicating an excellent color fastness where color change can only be prevented by dyeing. Conversely, the color difference of Gardenia-dyed Hanji after the UV irradiation was very high at 15.2 , followed by 11.6 of Violetroot cromwell, considered a dye material with poor color fastness. Amur cork-tree bark, Cochineal, ethanoldiluted Ottchil, and Sappan wood were used as dyes with a color difference of 6 to 9 .

UV irradiation decreased the dyeing yield on most of the dyed Hanjis, but for Meok-dyed Hanji, it slightly increased. The color value of most of the natural dyed Hanjis increased, while those of Alnus firma, Amur cork-tree, and Meok-dyed ones decreased. After $72 \mathrm{hr}$. of UV irradiation, most of the natural dyed Hanji did not change the color series, but Violet-root cromwell dyed Hanji changed from 5.8YR to 2.7Y, and Sappan wood changed from $8.2 \mathrm{YR}$ to $0.2 \mathrm{Y}$. 
JeongKwan $\mathrm{ROH} \cdot$ Hyun-Jin JO

Table 3. Color characteristics of various natural dyed Hanjis after $72 \mathrm{hr}$. UV radiation

\begin{tabular}{|c|c|c|c|c|c|c|c|c|c|c|}
\hline \multirow{2}{*}{$\begin{array}{l}\text { Type of } \\
\text { natural dye }\end{array}$} & \multirow{2}{*}{$\begin{array}{c}\text { UV } \\
\text { radiation } \\
(\mathrm{hr} .)\end{array}$} & \multirow{2}{*}{$\begin{array}{c}\lambda \max \\
(\mathrm{nm})\end{array}$} & \multirow{2}{*}{$\mathrm{K} / \mathrm{S}$} & \multicolumn{4}{|c|}{ CIE Lab } & \multicolumn{3}{|c|}{ Munsell's value } \\
\hline & & & & $\mathrm{L}^{*}$ & $a^{*}$ & $\mathrm{~b}^{*}$ & $\triangle \mathrm{E}$ & $\mathrm{H}$ & V & $\mathrm{C}$ \\
\hline \multirow{2}{*}{1} & 0 & 360 & 0.49 & 86.81 & -0.30 & 7.96 & & $4.3 \mathrm{Y}$ & 8.58 & 0.94 \\
\hline & 72 & 360 & 0.49 & 87.36 & -0.63 & 10.06 & 2.23 & $5.1 \mathrm{Y}$ & 8.64 & 1.19 \\
\hline \multirow{2}{*}{2} & 0 & 360 & 1.32 & 84.56 & -0.09 & 15.86 & 8.21 & $4.0 \mathrm{Y}$ & 8.37 & 2.02 \\
\hline & 72 & 360 & 0.82 & 85.80 & -0.58 & 14.99 & 1.24 & $4.8 \mathrm{Y}$ & 8.5 & 1.86 \\
\hline \multirow{2}{*}{3} & 0 & 360 & 2.66 & 75.33 & 4.27 & 22.78 & 19.25 & $1.2 \mathrm{Y}$ & 7.45 & 3.44 \\
\hline & 72 & 360 & 1.59 & 80.85 & 2.41 & 21.88 & 6.33 & $2.3 \mathrm{Y}$ & 8.01 & 3.14 \\
\hline \multirow{2}{*}{4} & 0 & 360 & 4.19 & 77.11 & 2.83 & 24.20 & 19.14 & $2.3 \mathrm{Y}$ & 7.63 & 3.50 \\
\hline & 72 & 360 & 3.96 & 74.10 & 4.44 & 25.52 & 3.17 & $1.6 \mathrm{Y}$ & 7.33 & 3.83 \\
\hline \multirow{2}{*}{5} & 0 & 360 & 1.00 & 84.33 & 0.52 & 24.82 & 17.06 & $4.7 \mathrm{Y}$ & 8.39 & 3.41 \\
\hline & 72 & 360 & 0.41 & 87.15 & -0.47 & 10.89 & 15.22 & $5.1 \mathrm{Y}$ & 8.63 & 1.32 \\
\hline \multirow{2}{*}{6} & 0 & 360 & 1.23 & 85.40 & -0.33 & 13.29 & 5.50 & $3.9 \mathrm{Y}$ & 8.45 & 1.64 \\
\hline & 72 & 360 & 0.86 & 86.19 & -0.34 & 13.34 & 0.67 & $4.2 \mathrm{Y}$ & 8.53 & 1.65 \\
\hline \multirow{2}{*}{7} & 0 & 360 & 1.40 & 85.45 & -0.28 & 14.44 & 6.61 & $4.2 \mathrm{Y}$ & 8.46 & 1.80 \\
\hline & 72 & 360 & 0.77 & 87.20 & -0.41 & 11.68 & 3.06 & $4.5 \mathrm{Y}$ & 8.63 & 1.42 \\
\hline \multirow{2}{*}{8} & 0 & 360 & 1.91 & 86.38 & -4.31 & 22.18 & 14.79 & $9.8 \mathrm{Y}$ & 8.57 & 2.75 \\
\hline & 72 & 360 & 0.73 & 85.77 & -0.05 & 15.39 & 8.42 & $4.1 \mathrm{Y}$ & 8.5 & 1.96 \\
\hline \multirow{2}{*}{9} & 0 & 370 & 9.44 & 28.92 & 0.68 & 2.57 & 58.05 & & 2.82 & 0.42 \\
\hline & 72 & 370 & 9.69 & 28.67 & 0.68 & 2.63 & 0.03 & & 2.8 & 0.43 \\
\hline \multirow{2}{*}{10} & 0 & 650 & 6.04 & 38.30 & -2.64 & -14.32 & 53.34 & $3.7 \mathrm{~PB}$ & 3.67 & 3.45 \\
\hline & 72 & 650 & 5.82 & 39.59 & -3.19 & -14.36 & 0.98 & $3.3 \mathrm{~PB}$ & 3.79 & 3.53 \\
\hline \multirow{2}{*}{11} & 0 & 530 & 2.69 & 49.74 & 19.58 & 1.10 & 42.54 & 7.7RP & 4.84 & 4.93 \\
\hline & 72 & 530 & 2.40 & 50.78 & 17.43 & 1.72 & 3.14 & $8.3 \mathrm{RP}$ & 4.94 & 4.43 \\
\hline \multirow{2}{*}{12} & 0 & 360 & 0.96 & 76.07 & 4.01 & 7.84 & 11.49 & $5.8 \mathrm{YR}$ & 7.49 & 1.57 \\
\hline & 72 & 360 & 0.57 & 85.38 & 0.61 & 12.23 & 11.59 & $2.7 \mathrm{Y}$ & 8.45 & 1.59 \\
\hline \multirow{2}{*}{13} & 0 & 360 & 1.05 & 78.26 & 5.81 & 8.82 & 10.57 & $3.2 \mathrm{YR}$ & 7.71 & 2.15 \\
\hline & 72 & 360 & 0.70 & 82.34 & 2.89 & 10.62 & 6.67 & 8.8YR & 8.13 & 1.71 \\
\hline \multirow{2}{*}{14} & 0 & 360 & 1.39 & 76.93 & 8.63 & 21.23 & 18.77 & $8.2 \mathrm{YR}$ & 7.62 & 3.75 \\
\hline & 72 & 360 & 1.19 & 79.99 & 4.54 & 18.75 & 5.79 & $0.2 \mathrm{Y}$ & 7.92 & 2.93 \\
\hline \multirow{2}{*}{15} & 0 & 360 & 0.94 & 91.70 & 2.78 & -12.83 & 21.59 & & 9.02 & 3.94 \\
\hline & 72 & 370 & 0.37 & 92.01 & 0.55 & -5.45 & 7.37 & & 9.08 & 2.18 \\
\hline
\end{tabular}

Fig. 2 shows the comparison of color differences of the natural dyed Hanji after exposure to UV irradiation for 24, 48, and $72 \mathrm{hr}$. Regardless of the UV irradiation time, the color difference in turpentine-diluted Ottchil, Pagoda tree, Meok, and Indigo-dyed Hanjis was little, on the other hand the color difference in Gardenia, Violet- 


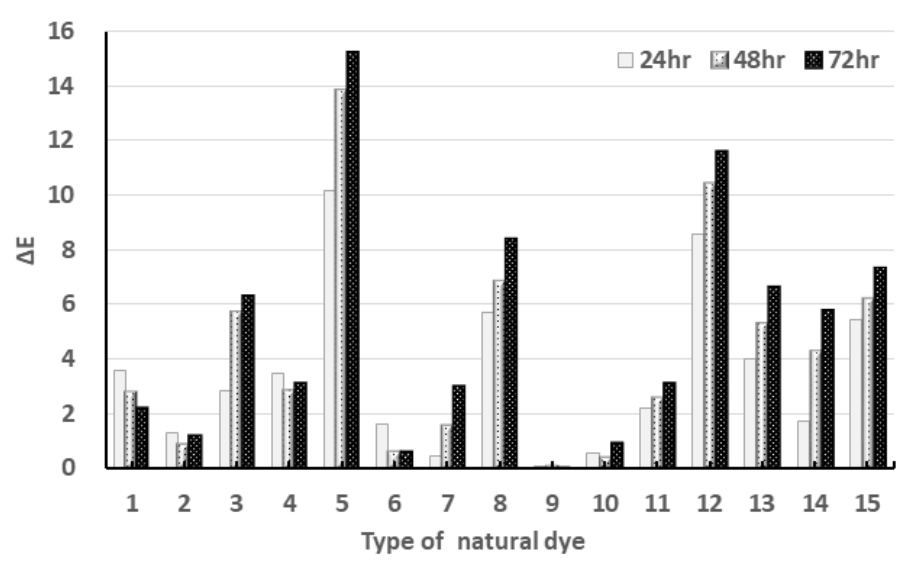

Fig. 2. Comparison of $\triangle \mathrm{E}$ according to $\mathrm{UV}$ radiation time for each natural dyed Hanjis.

root cromwell, and Amur cork-tree-dyed Hanjis was big. For most of the natural dyed Hanji, prolongation of UV irradiation time resulted in increase of the color difference and gradual color discoloration. However, turpentine-diluted Ottchil, Alnus firma, and Pagoda-dyed Hanji showed that the color difference at $24 \mathrm{hr}$. UV irradiation was smaller than that at $72 \mathrm{hr}$. UV irradiation.

\subsection{Color characteristics and color fastness of the natural dyed Hanji after post-mordanting}

3.2.1. Color characteristics of the natural dyed Hanji after post-mordanting

Table 4 and Fig. 3 show the results of post-mordanting Hanji dyed with 13 natural dyes using $\mathrm{Al}, \mathrm{Cu}$, and Fe mordants. The color difference of the post-mordanted dyed Hanji by the three mordants was very big. Even none-dyed Hanji showed color difference of 0.29, 2.58, and 10.32 by $\mathrm{Al}, \mathrm{Cu}$, and $\mathrm{Fe}$ mordants, respectively. Thus, there was almost no difference after $\mathrm{Al}$ mordant, but a clear difference for $\mathrm{Cu}$, and in Fe mordants, there was a very big color difference due to a decrease in $\mathrm{L}^{*}$

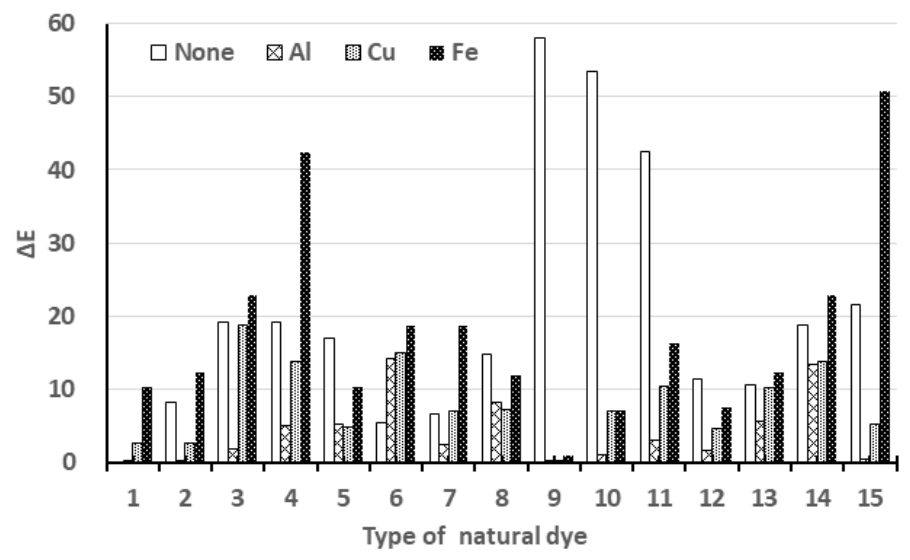

Fig. 3. Color difference of various natural dyed Hanjis after post-mordanting. 
JeongKwan $\mathrm{ROH} \cdot$ Hyun-Jin JO

Table 4. Color characteristics of post-mordanted natural dyed Hanjis

\begin{tabular}{|c|c|c|c|c|c|c|c|c|c|c|}
\hline \multirow{2}{*}{$\begin{array}{c}\text { Type of } \\
\text { natural dye }\end{array}$} & \multirow{2}{*}{$\begin{array}{c}\text { Type of } \\
\text { post- } \\
\text { mordanting }\end{array}$} & \multirow{2}{*}{$\begin{array}{l}\lambda \max \\
(\mathrm{nm})\end{array}$} & \multirow[b]{2}{*}{$\mathrm{K} / \mathrm{S}$} & \multicolumn{4}{|c|}{ CIE Lab } & \multicolumn{3}{|c|}{ Munsell's value } \\
\hline & & & & $\mathrm{L}^{*}$ & $a^{*}$ & $\mathrm{~b}^{*}$ & $\triangle \mathrm{E}$ & $\mathrm{H}$ & V & $\mathrm{C}$ \\
\hline \multirow{4}{*}{$\begin{array}{c}1 \\
\text { Control } \\
\text { (Hanji) }\end{array}$} & None & 360 & 0.49 & 86.81 & -0.30 & 7.96 & & $4.3 \mathrm{Y}$ & 8.58 & 20.94 \\
\hline & $\mathrm{Al}$ & 360 & 0.43 & 86.99 & -0.44 & 7.78 & 0.29 & $4.8 \mathrm{Y}$ & 8.60 & 0.91 \\
\hline & $\mathrm{Cu}$ & 360 & 0.58 & 85.44 & -1.72 & 9.64 & 2.58 & $8.8 \mathrm{Y}$ & 8.44 & 1.10 \\
\hline & $\mathrm{Fe}$ & 360 & 1.36 & 80.34 & 2.45 & 15.52 & 10.32 & $1.2 \mathrm{Y}$ & 7.94 & 2.26 \\
\hline \multirow{4}{*}{$\begin{array}{c}2 \\
\text { Ottchil } \\
\text { (Turpentine) }\end{array}$} & None & 360 & 1.32 & 84.56 & -0.09 & 15.86 & 8.21 & $4.0 \mathrm{Y}$ & 8.37 & 2.02 \\
\hline & $\mathrm{Al}$ & 360 & 1.27 & 84.73 & -0.28 & 15.81 & 0.27 & $4.3 \mathrm{Y}$ & 8.39 & 2.00 \\
\hline & $\mathrm{Cu}$ & 360 & 1.43 & 82.24 & -0.55 & 16.95 & 2.60 & $4.9 \mathrm{Y}$ & 8.14 & 2.18 \\
\hline & $\mathrm{Fe}$ & 360 & 2.32 & 73.70 & 4.80 & 19.09 & 12.33 & $0.2 \mathrm{Y}$ & 7.28 & 2.98 \\
\hline \multirow{4}{*}{$\begin{array}{c}3 \\
\text { Ottchil } \\
\text { (Ethanol) }\end{array}$} & None & 360 & 2.66 & 75.33 & 4.27 & 22.78 & 19.25 & $1.2 \mathrm{Y}$ & 7.45 & 3.44 \\
\hline & $\mathrm{Al}$ & 360 & 2.74 & 73.69 & 3.96 & 21.94 & 1.86 & $1.4 \mathrm{Y}$ & 7.28 & 3.29 \\
\hline & $\mathrm{Cu}$ & 360 & 3.23 & 59.56 & 2.35 & 12.91 & 18.70 & $2.0 \mathrm{Y}$ & 5.83 & 1.91 \\
\hline & $\mathrm{Fe}$ & 360 & 3.88 & 56.26 & 1.02 & 10.74 & 22.79 & $3.2 \mathrm{Y}$ & 5.49 & 1.53 \\
\hline \multirow{4}{*}{$\begin{array}{c}4 \\
\text { Alnus firma }\end{array}$} & None & 360 & 4.19 & 77.11 & 2.83 & 24.20 & 19.14 & $2.3 \mathrm{Y}$ & 7.63 & 3.50 \\
\hline & $\mathrm{Al}$ & 360 & 4.38 & 74.30 & 2.89 & 28.47 & 5.11 & $2.9 \mathrm{Y}$ & 7.35 & 4.09 \\
\hline & $\mathrm{Cu}$ & 360 & 4.99 & 63.64 & 5.77 & 24.50 & 13.79 & $0.8 \mathrm{Y}$ & 6.27 & 3.82 \\
\hline & $\mathrm{Fe}$ & 360 & 6.04 & 40.75 & 1.47 & 2.53 & 42.35 & $5.4 \mathrm{YR}$ & 3.96 & 0.48 \\
\hline \multirow{4}{*}{$\begin{array}{c}5 \\
\text { Gardenia } \\
\text { seeds }\end{array}$} & None & 360 & 1.00 & 84.33 & 0.52 & 24.82 & 17.06 & $4.7 \mathrm{Y}$ & 8.39 & 3.41 \\
\hline & $\mathrm{Al}$ & 360 & 0.73 & 85.72 & -0.88 & 20.00 & 5.21 & $5.8 \mathrm{Y}$ & 8.51 & 2.59 \\
\hline & $\mathrm{Cu}$ & 360 & 0.96 & 83.31 & -1.75 & 20.55 & 4.94 & $7.3 \mathrm{Y}$ & 8.26 & 2.66 \\
\hline & $\mathrm{Fe}$ & 360 & 1.73 & 76.05 & 4.17 & 19.93 & 10.28 & $1.0 \mathrm{Y}$ & 7.52 & 3.04 \\
\hline \multirow{4}{*}{$\begin{array}{c}6 \\
\text { Pagoda tree }\end{array}$} & None & 360 & 1.23 & 85.40 & -0.33 & 13.29 & 5.50 & $3.9 \mathrm{Y}$ & 8.45 & 1.64 \\
\hline & $\mathrm{Al}$ & 360 & 0.95 & 84.17 & -2.25 & 27.41 & 14.30 & $6.6 \mathrm{Y}$ & 8.36 & 3.59 \\
\hline & $\mathrm{Cu}$ & 360 & 1.11 & 79.34 & 0.40 & 27.06 & 15.06 & $4.4 \mathrm{Y}$ & 7.87 & 3.77 \\
\hline & $\mathrm{Fe}$ & 360 & 2.30 & 67.81 & 3.69 & 18.33 & 18.74 & $1.2 \mathrm{Y}$ & 6.67 & 2.77 \\
\hline \multirow{4}{*}{$\begin{array}{c}7 \\
\text { Clove tree }\end{array}$} & None & 360 & 1.40 & 85.45 & -0.28 & 14.44 & 6.61 & $4.2 \mathrm{Y}$ & 8.46 & 1.80 \\
\hline & $\mathrm{Al}$ & 360 & 1.12 & 85.34 & -1.57 & 16.57 & 2.49 & $6.0 \mathrm{Y}$ & 8.45 & 2.01 \\
\hline & $\mathrm{Cu}$ & 360 & 1.45 & 80.84 & -0.60 & 19.69 & 7.00 & $4.9 \mathrm{Y}$ & 8.00 & 2.59 \\
\hline & $\mathrm{Fe}$ & 360 & 2.55 & 67.48 & 5.09 & 15.32 & 18.78 & 9.1YR & 6.63 & 2.53 \\
\hline \multirow{4}{*}{$\begin{array}{c}8 \\
\text { Amur } \\
\text { cork-tree }\end{array}$} & None & 360 & 1.91 & 86.38 & -4.31 & 22.18 & 14.79 & $9.8 \mathrm{Y}$ & 8.57 & 2.75 \\
\hline & $\mathrm{Al}$ & 360 & 0.92 & 86.47 & -2.27 & 14.16 & 8.28 & $8.0 \mathrm{Y}$ & 8.56 & 1.67 \\
\hline & $\mathrm{Cu}$ & 360 & 1.26 & 84.49 & -2.75 & 15.39 & 7.22 & $9.8 \mathrm{Y}$ & 8.36 & 1.84 \\
\hline & $\mathrm{Fe}$ & 360 & 1.89 & 78.02 & 4.17 & 21.06 & 11.96 & $0.9 \mathrm{Y}$ & 7.72 & 3.20 \\
\hline \multirow{4}{*}{$\begin{array}{c}9 \\
\text { Chinese ink }\end{array}$} & None & 370 & 9.44 & 28.92 & 0.68 & 2.57 & 58.05 & & 2.82 & 0.42 \\
\hline & $\mathrm{Al}$ & 370 & 9.46 & 28.74 & 0.62 & 2.34 & 0.29 & & 2.81 & 0.39 \\
\hline & $\mathrm{Cu}$ & 360 & 9.54 & 28.99 & 0.65 & 2.61 & 0.09 & & 2.84 & 0.42 \\
\hline & $\mathrm{Fe}$ & 360 & 10.90 & 28.49 & 0.71 & 3.33 & 0.87 & & 2.79 & 0.54 \\
\hline \multirow{4}{*}{$\begin{array}{c}10 \\
\text { Indigo }\end{array}$} & None & 650 & 6.04 & 38.30 & -2.64 & -14.32 & 53.34 & $3.7 \mathrm{~PB}$ & 3.67 & 3.45 \\
\hline & $\mathrm{Al}$ & 650 & 6.22 & 38.09 & -3.06 & -13.27 & 1.16 & $3.1 \mathrm{~PB}$ & 3.65 & 3.20 \\
\hline & $\mathrm{Cu}$ & 640 & 6.62 & 34.63 & -1.52 & -8.55 & 6.93 & $3.4 \mathrm{~PB}$ & 3.34 & 1.90 \\
\hline & $\mathrm{Fe}$ & 630 & 6.98 & 33.71 & -1.92 & -8.99 & 7.08 & 3.3PB & 3.25 & 2.01 \\
\hline \multirow{4}{*}{$\begin{array}{c}11 \\
\mathrm{Lac}\end{array}$} & None & 530 & 2.69 & 49.74 & 19.58 & 1.10 & 42.54 & 7.7RP & 4.84 & 4.93 \\
\hline & $\mathrm{Al}$ & 360 & 3.34 & 50.09 & 22.29 & 2.31 & 2.99 & 8.6RP & 4.88 & 5.52 \\
\hline & $\mathrm{Cu}$ & 360 & 3.44 & 48.38 & 9.29 & 1.70 & 10.40 & 9.3RP & 4.70 & 2.42 \\
\hline & $\mathrm{Fe}$ & 360 & 4.20 & 45.34 & 3.81 & 1.76 & 16.38 & $5.1 \mathrm{R}$ & 4.40 & 0.92 \\
\hline
\end{tabular}


Table 4. Continued

\begin{tabular}{|c|c|c|c|c|c|c|c|c|c|c|}
\hline \multirow{2}{*}{$\begin{array}{l}\text { Type of } \\
\text { natural dye }\end{array}$} & \multirow{2}{*}{$\begin{array}{c}\text { Type of } \\
\text { post- } \\
\text { mordanting }\end{array}$} & \multirow{2}{*}{$\begin{array}{c}\lambda \max \\
(\mathrm{nm})\end{array}$} & \multirow{2}{*}{$\mathrm{K} / \mathrm{S}$} & \multicolumn{4}{|c|}{ CIE Lab } & \multicolumn{3}{|c|}{ Munsell's value } \\
\hline & & & & $\mathrm{L}^{*}$ & $a^{*}$ & $\mathrm{~b}^{*}$ & $\Delta \mathrm{E}$ & $\mathrm{H}$ & V & $\mathrm{C}$ \\
\hline \multirow{4}{*}{$\begin{array}{c}12 \\
\text { Violet-root } \\
\text { cromwell }\end{array}$} & None & 360 & 0.96 & 76.07 & 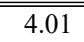 & 7.84 & 11.49 & "5.8YR & 7.49 & 1.57 \\
\hline & $\mathrm{Al}$ & 360 & 0.80 & 75.78 & 3.83 & 6.20 & 1.68 & 4.1YR & 7.45 & 1.42 \\
\hline & $\mathrm{Cu}$ & 360 & 1.09 & 73.11 & 0.51 & 7.24 & 4.62 & $1.8 \mathrm{YR}$ & 7.18 & 0.99 \\
\hline & $\mathrm{Fe}$ & 360 & 1.82 & 69.97 & 3.60 & 12.39 & 7.62 & $9.5 \mathrm{YR}$ & 6.88 & 1.98 \\
\hline \multirow{4}{*}{$\begin{array}{c}13 \\
\text { Cochineal }\end{array}$} & None & 360 & 1.05 & 78.26 & 5.81 & 8.82 & 10.57 & $3.2 \mathrm{YR}$ & 7.71 & 2.15 \\
\hline & $\mathrm{Al}$ & 360 & 0.84 & 77.41 & 10.83 & 6.26 & 5.69 & $5.8 \mathrm{YR}$ & 7.62 & 3.17 \\
\hline & $\mathrm{Cu}$ & 360 & 1.36 & 69.32 & 1.23 & 6.70 & 10.26 & $1.3 \mathrm{Y}$ & 6.79 & 0.98 \\
\hline & $\mathrm{Fe}$ & 360 & 2.19 & 66.64 & 2.27 & 10.77 & 12.30 & $0.5 \mathrm{Y}$ & 6.53 & 1.62 \\
\hline \multirow{4}{*}{$\begin{array}{c}14 \\
\text { Sappan } \\
\text { wood }\end{array}$} & None & 360 & 1.39 & 76.93 & 8.63 & 21.23 & 18.77 & $8.2 \mathrm{YR}$ & 7.62 & 3.75 \\
\hline & $\mathrm{Al}$ & 360 & 1.34 & 71.23 & 13.95 & 10.36 & 13.38 & 8.0YR & 7.00 & 3.86 \\
\hline & $\mathrm{Cu}$ & 360 & 1.59 & 68.19 & 8.90 & 10.60 & 13.77 & $2.2 \mathrm{YR}$ & 6.69 & 2.72 \\
\hline & $\mathrm{Fe}$ & 360 & 3.13 & 58.11 & 3.94 & 9.15 & 22.84 & 7.9YR & 5.67 & 1.62 \\
\hline \multirow{4}{*}{$\begin{array}{c}15 \\
\text { Copy paper }\end{array}$} & None & 360 & 0.94 & 91.70 & 2.78 & -12.83 & 21.59 & $9.4 \mathrm{~PB}$ & 9.02 & 3.94 \\
\hline & $\mathrm{Al}$ & 370 & 0.93 & 91.65 & 2.42 & -12.45 & 0.52 & $9.1 \mathrm{~PB}$ & 9.02 & 3.96 \\
\hline & $\mathrm{Cu}$ & 360 & 0.90 & 90.91 & -0.37 & -8.83 & 5.15 & 6.7PB & 8.95 & 3.43 \\
\hline & $\mathrm{Fe}$ & 360 & 5.55 & 73.39 & 13.04 & 33.43 & 50.79 & 8.3YR & 7.29 & 5.82 \\
\hline
\end{tabular}

and a large increase in $\mathrm{a}^{*}$ and $\mathrm{b}^{*}$. In addition, the color difference by Fe mordant was the biggest in all the dyed Hanji, and that of $\mathrm{Cu}$ mordant was bigger than $\mathrm{Al}$ mordant, except for Alnus firma and Amur cork-tree dyed Hanji. However, the color difference of Meok-dyed Hanji was less than 1, and almost no color change was observed for post-mordanting with the three mordants. The color difference for $\mathrm{Al}$ mordant of Hanji was 0.32, which was very small, but among the post-mordanted natural dyed Hanji by $\mathrm{Al}$, Hanji with a color difference of 5.0 or higher were Pagoda tree (14.3), Sappan wood (10.4), Amur cork-tree (8.3), Cochineal (5.7), Gardenia (5.2), and Alnus firma-dyed Hanji (5.1). Natural dyed Hanji with a color difference of 10.0 or more were ethanol-diluted Ottchil (18.7), Alnus firma (13.8), Pagoda tree (15.1), Sappan wood (13.8), Lac (10.4), and Cochineal (10.3) dyed Hanji treated with $\mathrm{Cu}$ mordant. According to Fe mordant, the color difference of Alnus firma (42.4) dyed Hanji was the biggest, followed by Sappan wood (22.8), ethanol-diluted Ottchil (22.8), Clove tree (18.8), and Pagoda tree (18.7) dyed Hanji. Violet-root cromwell (7.6) and Indigo (7.1)-dyed Hanji were smaller than none-dyed Hanji.

Almost no hue change was observed even when each natural dyed Hanji was post-mordanting with three types of mordant. However, the Fe mordant of Alnus firmadyed Hanji $(2.3 \mathrm{Y} \rightarrow 5.4 \mathrm{YR} 4.0 / 0.5)$, the Fe mordant of Clove tree $(4.2 \mathrm{Y} \rightarrow 9.1 \mathrm{YR} 6.6 / 2.5)$, the Fe mordant of $\mathrm{Lac}(7.7 \mathrm{RP} \rightarrow 5.1 \mathrm{R} 4.4 / 0.9)$, and the $\mathrm{Cu}$ and the $\mathrm{Fe}$ mordants of Cochineal $(\mathrm{Cu} 3.2 \mathrm{YR} \rightarrow 1.3 \mathrm{Y}$ 6.8/1.0, Fe $3.2 \mathrm{YR} \rightarrow 0.5 \mathrm{Y}$ 6.5/1.6) showed hue changes. Except for $\mathrm{Cu}$ mordant of Cochineal, hue change was observed in $\mathrm{Fe}$ mordant. It was discolored to almost black by $\mathrm{Fe}$ mordant of Alnus firma and Lac. Although the color Value differed depending on the mordants, it was similar to that of one before mordant for $\mathrm{Al}$ mordant, but in $\mathrm{Cu}$ or Fe mordant, most of them decreased and progressed to a rather dark color.

\subsubsection{Color fastness of post-mordanted natural dyed Hanji}

Fig. 4 shows the color fastness of Hanji dyed with natural dyes after post-mordanting with three mordants and exposure to $72 \mathrm{hr}$. of UV irradiation. There was slight 


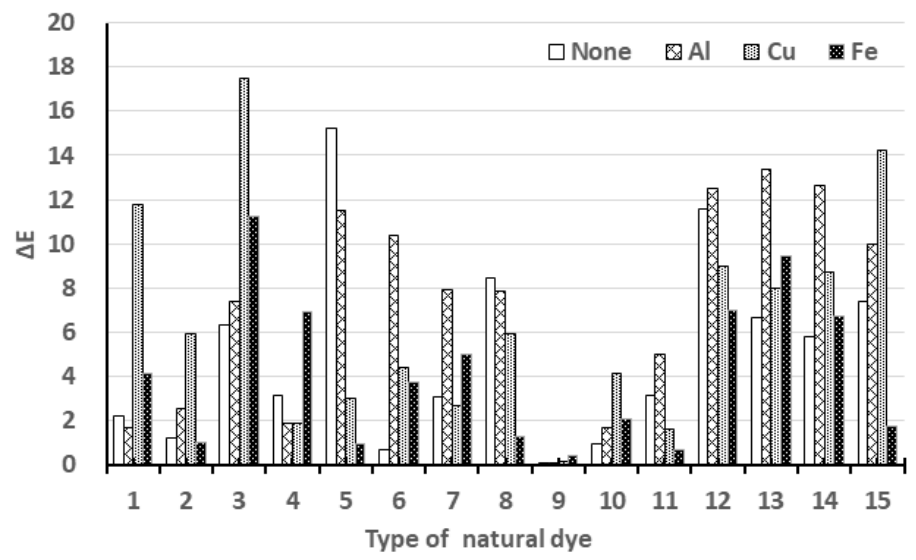

Fig. 4. Color difference of post mordanting natural dyed Hanjis after $72 \mathrm{hr}$. UV radiation.

change in hue after $72 \mathrm{hr}$. of UV irradiation on postmordanting Hanji base paper (Control). Al post-mordanting Hanji demonstrated a smaller color difference than Hanji itself, but the one Cu post-mordanted showed a significantly big color difference of 11.8 .

Meok-dyed Hanji showed color difference of less than 1.0 even after $72 \mathrm{hr}$. of UV irradiation for all three post-mordants. Among the 12 types of natural dyed Hanji excluding Meok-dyed Hanji, those with a color difference of less than 1.0 after $72 \mathrm{hr}$. of UV irradiation on Hanji without post-mordanting were Alnus firma and Indigo-dyed Hanji with excellent color fastness. However, there were cases where the color difference of dyed Hanji between after post-mordanting and after $72 \mathrm{hr}$. UV irradiation was smaller than that between before post-mordanting and after $72 \mathrm{hr}$. UV irradiation. Fe mordant on ethanol-diluted Ottchil-dyed Hanji (1.2 $\rightarrow$ 1.0), $\mathrm{Al}, \mathrm{Cu}$ mordants on Alnus firma-dyed Hanji (3.2 $\rightarrow$ 1.9), $\mathrm{Al}, \mathrm{Cu}$, and $\mathrm{Fe}$ mordants on Gardenia-dyed Hanji $(15.2 \rightarrow 11.5,3.0,1.0), \mathrm{Cu}$ mordant on Clove tree-dyed Hanji $(3.1 \rightarrow 2.7), \mathrm{Al}, \mathrm{Cu}$, and $\mathrm{Fe}$ mordants on Amur cork-tree-dyed Hanji $(8.4 \rightarrow 7.9,5.9,1.3), \mathrm{Cu}$ and $\mathrm{Fe}$ mordants on Lac-dyed Hanji $(3.1 \rightarrow 1.6,0.7), \mathrm{Cu}$ and $\mathrm{Fe}$ mordants on Violet-root cromwell dyed Hanji (11.6 $\rightarrow$ 9.0, 7.0), and $\mathrm{Al}, \mathrm{Cu}$, and $\mathrm{Fe}$ mordants on Gardeniadyed Hanji $(15.2 \rightarrow 11.5,3.0,1.0)$ drove improvement in color fastness of them. Especially, Gardenia-dyed Hanji, which has a tendency to discolor easily, might be prevented the discoloration by Fe post-mordanting.

Post-mordanting turpentine-diluted Ottchil Hanji had a hue change by $\mathrm{Fe}$ post-mordanting $(0.2 \mathrm{Y} \rightarrow 9.9 \mathrm{YR})$. However, even after $72 \mathrm{hr}$. of UV irradiation, all three types of post-mordants showed a relatively small color difference. In particular, the color difference of $\mathrm{Fe}$ post-mordanting Hanji was very small at 1.0 despite the change in hue, exhibiting excellent color fastness. Postmordanting ethanol-diluted Ottchil staining Hanji showed a big color difference after $72 \mathrm{hr}$. of UV irradiation for all three types of post-mordants, indicating low color fastness. Hue of Alnus firma-dyed Hanji was changed from 5.4YR to black due to Fe mordant, and the color difference increased. For $\mathrm{Al}$ and $\mathrm{Cu}$ mordants, color fastness improved as the color difference decreased after $72 \mathrm{hr}$. of UV irradiation. The Gardenia-dyed Hanji showed very poor color fastness, but it was greatly improved by the post-mordanting as in Gardenia-dyed Hanji, which showed superior color fastness. The Pagoda-tree dyed Hanji without post-mordanting treatment showed very good color fastness, but when post-mordant treatment was applied, the color difference of all three types of mordants increased significantly, especially $\mathrm{Al}$ post-mordanting. Post-mordanting Clove tree-dyed Hanji 
showed almost the same color difference as Clove treedyed Hanji before mordants treatment in $\mathrm{Cu}$ and $\mathrm{Fe}$ mordants even after $72 \mathrm{hr}$. of UV irradiation, but $\mathrm{Al}$ mordant was significantly increased. Post-mordanting Amur cork-tree-dyed Hanji showed a smaller color difference than that of Amur cork-tree-dyed Hanji before mordant treatment in all three types of mordants even after $72 \mathrm{hr}$. of UV irradiation. The hue also changed from $0.9 \mathrm{Y}$ to $9.8 \mathrm{YR}$ by Fe mordant. The color fastness of Indigo-dyed Hanji before mordanting was very good, but the color difference slightly increased due to post-mordanting. In Lac-dyed Hanji, the color difference decreased by $\mathrm{Cu}$ and $\mathrm{Fe}$ post-mordanting, while it increased in $\mathrm{Al}$ post-mordanting. The color fastness observed in Fe post-mordanting Lac dyeing Hanji was superior. In the case of Lac-dyed Hanji's $\mathrm{Cu}$ postmordanting, the hue changed from 9.3RP to $1.3 \mathrm{R}$. The hue of Violet-root cromwell dyed Hanji was changed from 4.1YR to $3.5 \mathrm{Y}$ due to $\mathrm{Al}$ post-mordanting, and although color fastness was poor overall, it was slightly improved with $\mathrm{Fe}$ and $\mathrm{Cu}$ post-mordanting. Both Cochineal and Sappan wood-dyed Hanji showed a color difference of 6.7, which was increased by the postmordanting, especially for Al post- mordanting.

As shown above, the color and color fastness were significantly different depending on the type of natural dye and the presence or the absence of post-mordant treatment. Therefore, when dyeing Hanji with natural dyes, it is recommended to dye with sufficient knowledge and information about the desired color and fastness.

\section{CONCLUSION}

The results of comparing and examining the color characteristics and changes in color and color fastness after post-mordanting on 13 types of natural dyed Hanji, which were big as it was manufactured manually without cutting and were dyed with 11 types of plant natural dyes and two types of animal natural dyes are as follow:
1) Before dyeing, the hue of Hanji was 4.3Y, with considerably high $\mathrm{L}^{*}$ and $\mathrm{V}$ values, indicating a yellowish color that was close to white.

2) Meok, Indigo, and Lac showed high dyeing yield and color difference among 13 natural dyeing materials, and Violet-root cromwell and Gardenia seeds showed low dyeing yield (less than 1).

3) Hanji dyed with two types of Ottchils, Alnus firma fruit, Gardenia seeds, Pagoda tree seeds, and Clove tree displayed a yellowish color $(\mathrm{H})$ of 1.24.7Y while Amur cork-tree bark expressed a yellow color close to green with $9.8 \mathrm{Y}$.

4) Meok-dyed Hanji showed considerably high dyeing yield and color difference, which was black, and had a V of 2.82 and a $\mathrm{C}$ of 0.42.

5) Indigo-dyed Hanji showed a big color difference and displayed a blue-ish hue with 3.7PB. The hue of Hanji dyed with Lac, a natural animal dye, was purple at 7.7RP. The hues of Hanji dyed with the plant Violet-root cromwell, Sappan wood, and animal Cochineal were 5.8YR, 3.2YR, and 8.2YR, respectively, and all displayed an orange-ish color.

6) The color difference after exposure to $72 \mathrm{hr}$. of UV irradiation was less than that of the undyed Hanji with excellent color fastness with turpentinediluted Ottchil, Pagoda, Meok, and Indigo-dyed Hanji. Gardenia and Violet-root cromwell dyed Hanji showed substantially poor color fastness.

7) The color difference of natural dyed Hanji after post-mordanting by $\mathrm{Al}, \mathrm{Cu}$, and $\mathrm{Fe}$ mordants was diverse. Overall, the color difference due to $\mathrm{Fe}$ mordant was the biggest, and $\mathrm{Cu}$ mordant was bigger than $\mathrm{Al}$ mordant, except for Alnus firma and Amur cork tree-dyed Hanji. Changes in hue are as follows: Alnus firma $\mathrm{Fe}$ mordant $(2.3 \mathrm{Y} \rightarrow$ 5.4YR), Clove tree Fe mordant (4.2Y $\rightarrow 9.1 \mathrm{YR})$, Lac's Fe mordant (7.7RP $\rightarrow 5.1 \mathrm{R})$, and Cochineal's $\mathrm{Cu}$ and $\mathrm{Fe}$ mordants $(\mathrm{Cu} 3.2 \mathrm{YR} \rightarrow 1.3 \mathrm{Y}, \mathrm{Fe}$ $3.2 \mathrm{YR} \rightarrow 0.5 \mathrm{Y}$ ). However, the color difference of 
Meok-dyed Hanji was less than 1, and almost no color change was observed as the post-mordanting by the three mordant dyes.

8) There was no color change observed for postmordanting Hanji base paper (Control) after exposure to $72 \mathrm{hr}$. of UV irradiation, and while $\mathrm{Al}$ post-mordanting Hanji base paper had a smaller color difference than the Hanji base paper itself, $\mathrm{Cu}$ post-mordanting showed a considerable color difference with 11.8. Meok-dyed Hanji showed excellent fastness with less than 1.0 color difference even after exposure to $72 \mathrm{hr}$. of UV irradiation for all three types of post-mordanting.

9) Fe mordant on ethanol-diluted Ottchil-dyed Hanji $(1.2 \rightarrow 1.0), \mathrm{Al}, \mathrm{Cu}$ mordants on Alnus firma-dyed Hanji $(3.2 \rightarrow 1.9), \mathrm{Al}, \mathrm{Cu}$, and $\mathrm{Fe}$ mordants on Gardenia-dyed Hanji $(15.2 \rightarrow 11.5,3.0,1.0), \mathrm{Cu}$ mordant on Clove tree-dyed Hanji $(3.1 \rightarrow 2.7), \mathrm{Al}$, $\mathrm{Cu}$, and $\mathrm{Fe}$ mordant on Amur cork-tree-dyed Hanji $(8.4 \rightarrow 7.9,5.9,1.3), \mathrm{Cu}$ and Fe mordant on Lacdyed Hanji $(3.1 \rightarrow 1.6,0.7), \mathrm{Cu}$ and $\mathrm{Fe}$ mordants on Violet-root cromwell dyed Hanji (11.6 $\rightarrow$ 9.0, 7.0), and $\mathrm{Al}, \mathrm{Cu}$, and $\mathrm{Fe}$ mordants on Gardenia-dyed Hanji $(15.2 \rightarrow 11.5,3.0,1.0)$ drove improvement in color fastness of them. As a result, color fastness was improved by post-mordanting, especially, Gardenia-dyed Hanji having tendency to discolor easily, was almost prevented by Fe post-mordanting.

\section{CONFLICT of INTEREST}

No potential conflict of interest relevant to this article was reported.

\section{ACKNOWLEDGMENT}

This work was supported by Gyeongsang National University Grant in 2020-2021.

\section{REFERENCES}

Choi, T.H., Yoo, S.I., Lee, S.H., Jeong, H.W., Yang, E.J. 2009. Natural dyeing of Hanji with Alnus japonica fruit extractive. Journal of the Korean Wood Science and Technology 37(4): 414-420.

Choi, T.H. 2006. Natural dyeing characteristics of Korean traditional paper. Journal of the Korean Wood Science and Technology 34(3): 90-98.

Hadi, Y.S., Massijaya, M.Y., Abdillah, I.B., Pari, G., Arsyad, W.O.M. 2020. Color change and resistance to subterranean termite attack of Mangium (Acacia mangium) and Sengon (Falcataria moluccana) smoked wood. Journal of the Korean Wood Science and Technology 48(1): 1-11.

Han, Y., Lee, S.M., Choi, J., Park, C.Y. 2021. A study on classification of wood cultural resources in South Korea. Journal of the Korean Wood Science and Technology 49(5): 430-452.

Han, Y., Lee, S. 2021a. Investigation on the awareness and preference for wood culture to promote the value of wood: I . Awareness of wood and cultural experience. Journal of the Korean Wood Science and Technology 49(6): 616-642.

Han, Y., Lee, S.M. 2021b. Investigation on the awareness and preference for wood to promote the value of wood: II. Awareness of wood cultural resources. Journal of the Korean Wood Science and Technology 49(6): 643-657.

Jeon, C., Kim, S.J., Moon, J. 1999. Properties of indigenous Korean paper (Hanji): Classification of oebal (single frame) papermaking methods. Journal of the Korean Wood Science and Technology 27(1): 88104.

Jeon, C. 2002. The effect of paper making methods and dochim of handmade Korean paper (Hanji) on the strength. Journal of the Korean Wood Science and Technology 30(2): 134-143.

Jeon, C. 2003. Studies on the dyeing of Hanji by natural 
dye-stuffs (II): With a focus on the onion-peelings. Journal of Korea Technical Association of the Pulp and Paper Industry 35(1): 48-53.

Jeon, C., Ahn, Y.H., Jeon, H.J. 2006. Studies on the dyeing of Hanji by natural dye-stuffs (III): With a focus on the mugwort. Journal of Korea Technical Association of the Pulp and Paper Industry 38(3): 61-65.

Jeon, C., Ahn, Y.H., Jeon, H.J. 2006. Studies on the dyeing of Hanji by natural dye-stuffs (IV): With a focus on the clove tree. Journal of Korea Technical Association of the Pulp and Paper Industry 38(3): 66-71.

Jo, H.J., Lee, S.K., Lee, H.J., Kang, H.Y., Choi, D.H., Choi. I.G. 2007. The dyeing properties of Hanji by Neolitsea sericea Koidz extracts. Journal of Korea Technical Association of the Pulp and Paper Industry 39(2): $60-67$.

Ju, S.G., Roh, J.K. 2020. Manufacturing regenerated woody dyed fiber from waste MDF using natural dyes. Journal of the Korean Wood Science and Technology 48(2): 154-165.

Lee, H.W., Lee, E.J. 2021. Effects of hot-air heat treatment on the surface color of Phyllostachys bambusoides bamboo. Journal of the Korean Wood Science and Technology 49(6): 566-573.

Lee, S.H., Yoo, S.I., Hypnosis, M.K. Shin, S., Choi, T.H. 2009. Natural dyeing characteristics of black color to the Korean traditional hand-made paper (Hanji). Journal of the Korean Wood Science and Technology 37(4): 406-413.

Lee, S.H., Yoo, S.I., Choi, T.H. 2009. Natural dyeing characteristics of Korean traditional paper with smoke tree (Cotinus coggygria Scop). Journal of Korea Technical Association of the Pulp and Paper Industry 41(2): 40-46.

Park, J.H., Park, J.H., Kim, S.C. 2020. A study on application of enzyme additives to improve drying speed of Urushi Lacquer. Journal of the Korean
Wood Science and Technology 48(3): 326-344.

Park, M.O., Yoon, S.L. 2009. Properties of natural dyeing of bast fiber (part 1): Properties of dye and extraction condition of sappan wood, gardenia and gallnut. Journal of Korea Technical Association of the Pulp and Paper Industry 41(3): 49-59.

Park, M.O., Yoon, S.L. 2010. Properties of natural dyeing of bast fiber (part 2) Pre mordanting dyeing of sappan wood, gardenia and gallnut. Journal of Korea Technical Association of the Pulp and Paper Industry 42(4): 1-14.

Park, M.O., Yoon, S.L. 2011. Properties of natural dyeing of bast fiber (part 3) Combination dyeing of gallnut-sappan wood and gardenia. Journal of Korea Technical Association of the Pulp and Paper Industry 43(1): $1-10$.

Priadi, T., Orfian, G., Cahyono, T.D., Iswanto, A.H. 2020. Dimensional stability, color change, and durability of boron-MMA treated red jabon (Antochephalus macrophyllus) wood. Journal of the Korean Wood Science and Technology 48(3): 315-325.

Yoo, S.I., Oh, S.K., Lee, S.H., Choi, T.H. 2009. Dyeing of Hanji with flowers of pagoda tree (Sophora japonica). Journal of Korea Technical Association of the Pulp and Paper Industry 41(2): 34-39.

Yoo, S.I., Oh, U.M., Min, Y.R., Choi, T.H. 2011. Improvement on dyeability of Hanji with natural dyes using a (3-chloro-2-hydroxypropyl) trimethyl ammonium chloride. Journal of Korea Technical Association of the Pulp and Paper Industry 43(3): 88-97.

Yoo, S.I., Lee, S.H., Kwak, M.R., Choi, T.H. 2010. Properties of Hanji dyed with the persimmon juice. Journal of Korea Technical Association of the Pulp and Paper Industry 42(2): 82-87.

Yoon, S.L., Jo, H.J., Park, S.B., Kim, H.J., Kim, J.K., Kim, S.I. 1996. Studies on wallpaper making using Hanji (I): Making and properties of Hanji for wallpaper. Journal of Korea Technical Association of the Pulp and Paper Industry 24(4): 15-21. 